\title{
Modulation of Exposure to Static Magnetic Field Affects Targeted Therapy of Solid Tumors In Vivo
}

\author{
DONATA GELLRICH ${ }^{1}$, URSULA SCHMIDTMAYER ${ }^{2}$, JONAS ECKRICH ${ }^{3}$, \\ JAN HAGEMANN ${ }^{3}$, SVEN BECKER $^{3}$ and SEBASTIAN STRIETH ${ }^{3}$ \\ ${ }^{1}$ Department of Otorhinolaryngology, Head and Neck Surgery, \\ Ludwig-Maximilians University (LMU), Munich, Germany; \\ ${ }^{2}$ Department of Otorhinolaryngology, Head and Neck Surgery, \\ Hannover Medical Center (MHH), Hannover, Germany; \\ ${ }^{3}$ Department of Otorhinolaryngology, Head and Neck Surgery, \\ Johannes Gutenberg University Medical Center Mainz, Mainz, Germany
}

\begin{abstract}
Background: Static magnetic fields (SMF) exhibit antitumoral activity and enhance the efficacy of chemotherapy by opening the tumor-blood barrier. This study aimed to analyze different SMF-exposure protocols on epidermal growth factor receptor (EGFR)-overexpressing tumors, as well as their combination with cetuximab. Materials and Methods: Experiments were performed in skinfold chamber preparations of C57Bl/6-and CD-1nu/nu mice bearing LLC-1 tumors. Animals were exposed to $587 \mathrm{mT}$ magnetic field following different exposure protocols. A subgroup received additional cetuximab injections. Using in vivo-fluorescence microscopy and planimetry, tumor angiogenesis, growth and microcirculation were repeatedly analyzed for 13 days. Results: In contrast to daily short SMF exposure, three-fold SMF exposure for $2 \mathrm{~h}$ led to a significant $46 \%$ reduction of tumor growth. Adding cetuximab to SMF exposure did not yield any benefit, although cetuximab monotherapy was highly effective (53\% reduction of tumor growth), indicating a potential interference of SMF and EGFR signaling. No effects on microcirculation, angiogenesis or leukocyte-endothelium interactions were documented. Conclusion: The use of SMF is promising in the treatment of solid tumors; however, it appears to interfere with EGFRtargeted therapy.
\end{abstract}

This study formed part of the research for the doctoral thesis of the Author Ursula Schmidtmayer.

Correspondence to: Donata Gellrich, MD, Department of Otorhinolaryngology, Head and Neck Surgery, LudwigMaximilians-Universität München, Marchioninistr. 15, D-81377 Munich, Germany. Tel: +49 89440073887, Fax: +49 89440076869, e-mail: Donata.Gellrich@med.uni-muenchen.de

Key Words: Squamous cell carcinoma, static magnetic field, targeted therapy, EGFR.
In the past two decades, research on magnetic fields and their effects on tumors has gained growing interest. Various studies confirmed that static magnetic fields (SMF) affect tumor cell biology in vitro (1) as well as in vivo $(2,3)$. However, the influence of various SMF exposure durations has not yet been studied in detail. Furthermore, there is little evidence of the effect of SMF on squamous cell carcinoma growth in vivo. Especially in recurrent squamous cell carcinoma of the head and neck (HNSCC), new treatment strategies are needed, when all curative treatment options surgery and radio(chemo)therapy - might have failed (4). The clinical application of magnetic fields to the head and neck region appears feasible by using specially designed head coils which have been in use for MRI diagnostics since the early 1980s (5).

Recent studies highlight the epidermal growth factor receptor (EGFR) as a potential primary target of magnetic fields (6-8). EGFR is overexpressed in over $90 \%$ of HNSCC cells (9), which is associated with an extraordinary aggressive behavior (10) and a worse prognosis and reduced survival $(11,12)$. Furthermore, enhanced resistance to chemotherapy and radiation therapy has been shown in patients with EGFR-overexpressing tumors (13, 14). Therefore, antibody-mediated blockage of EGFR signals has become proof-of-principle in favor of novel targeted therapy regimen's in HNSCC. Added to conventional chemotherapy, the first clinically-approved EGFR inhibitor, cetuximab, was found to significantly prolong the overall survival in patients with therapy-refractory HNSCCs (15).

For ligand-induced activation of the intracellular signal cascade, the dimerization of EGFR is crucial (16). However, SMFs induce clustering of EGFR in vitro $(6,7)$. Consequently, SMF exposure might interact with anti-EGFR therapy in vivo.

The combination of SMF exposure with conventional chemotherapy was shown to be synergistic in vitro (17) as 
Table I. Study treatment groups: The different study groups including their respective treatment schedules and controls are displayed.

\begin{tabular}{|c|c|c|c|}
\hline Treatment group & Mouse strain & SMF exposure & Injection on days $3,6,9$ \\
\hline A & $\mathrm{C} 57 \mathrm{~B} 1 / 6$ & $587 \mathrm{mT}$ for $120 \mathrm{~min}($ days $3,6,9)$ & $0.9 \% \mathrm{NaCl}$ \\
\hline $\mathrm{B}$ & $\mathrm{C} 57 \mathrm{Bl} / 6$ & $587 \mathrm{mT}$ for $35 \mathrm{~min}$ (days $3-11$ ) & $0.9 \% \mathrm{NaCl}$ \\
\hline Control & $\mathrm{C} 57 \mathrm{Bl} / 6$ & $0 \mathrm{mT}$ for $120 \mathrm{~min}$ (days $3,6,9$ ) & $0.9 \% \mathrm{NaCl}$ \\
\hline $\mathrm{A}+\mathrm{Cet}$ & $\mathrm{C} 57 \mathrm{~B} 1 / 6$ & $587 \mathrm{mT}$ for $120 \mathrm{~min}($ days $3,6,9)$ & $1 \mathrm{mg}$ Cetuximab \\
\hline $\mathrm{B}+\mathrm{Cet}$ & $\mathrm{C} 57 \mathrm{~B} 1 / 6$ & $587 \mathrm{mT}$ for $35 \mathrm{~min}$ (days $3-11$ ) & $1 \mathrm{mg}$ Cetuximab \\
\hline Cet control & $\mathrm{C} 57 \mathrm{~B} 1 / 6$ & $0 \mathrm{mT}$ for $120 \mathrm{~min}$ (days $3,6,9)$ & $1 \mathrm{mg}$ Cetuximab \\
\hline Immunodef. Cet & CD-1 nu/nu & $0 \mathrm{mT}$ for $120 \mathrm{~min}$ (days $3,6,9)$ & $1 \mathrm{mg}$ Cetuximab \\
\hline Immunodef. control & CD-1 nu/nu & $0 \mathrm{mT}$ for $120 \mathrm{~min}$ (days $3,6,9$ ) & $0.9 \% \mathrm{NaCl}$ \\
\hline
\end{tabular}

well as in vivo $(18,19)$. However, combination therapy using SMF exposure and targeted therapy, e.g. cetuximab, to our knowledge has not been addressed experimentally. Therefore, the present study aimed to analyze the effects of different SMF-exposure protocols in combination with EGFR-targeted therapy on HNSCC growth.

\section{Materials and Methods}

Animals. All animal experiments were in accordance with German legislation for the protection of animals and approved by the local government (Regierung von Oberbayern, Munich, Germany, Reference number 55.2-1-54-2531-97-10).

Experiments were carried out using male C57B1/6 mice and male CD-1nu/nu nude mice (11-13 weeks old, 27 \pm 2 g body weight; Charles River, Sulzbach, Germany). The treatment study comprised six groups of $\mathrm{C} 57 \mathrm{Bl} / 6$-mice $(\mathrm{n}=6$ each) and two groups of nude mice ( $n=6$ each). The animals were housed in single cages and had free access to tap water and standard laboratory food (ssniff; Spezialdiaeten GmbH, Soest, Germany).

Dorsal skinfold chamber preparation and tumor cell implantation. For quantitative fluorescence analysis of tumor microcirculation in vivo, a dorsal skinfold chamber consisting of two symmetrical titanium frames was surgically implanted into the dorsal skin of all mice as described in detail elsewhere $(20,21)$. The surgical procedure was carried under intraperitoneal anesthesia with ketamine (100 mg/kg b.w., Ketavet; Parke-Davis, Berlin, Germany) and xylazine (10 mg/kg b.w., Rompun; Bayer, Leverkusen, Germany). The mice were allowed to recover from anesthesia and microsurgery for a period of $48 \mathrm{~h}$. The chambers were well tolerated and the animals did not show any signs of discomfort. Chamber preparations fulfilling the criteria of an intact microcirculation and lacking sings of inflammation were inoculated with $1 \mu 1$ of dense tumor cell suspension $\left(\sim 1 \times 10^{5}\right.$ cells $)$ of syngeneic Lewis lung cancer cells (LLC-1; maintained in house) onto the striated skin muscle layer. High EGFR expression in Lewis lung cancer cells was proven by immunohistochemistry (22), and confirmed by fluorescence-activated cell scanning analysis.

Static magnetic field. SMFs were generated by a cylindrical permanent magnet providing a magnetic flux density of $587 \mathrm{mT}$, as described elsewhere (23). In order to avoid direct contact between the magnet and the chamber, a minimal distance between the two was always kept.
Experimental protocol. Trans-and epi-illuminated images of the whole tumor-hosting chamber preparations were taken by a digital camera to evaluate tumor growth by planimetry on days 3, 6, 9 and 13 after tumor cell implantation. On days 7 and 13 , when tumor microcirculation was well established, in vivo fluorescence microscopy was performed. The acquisition as well as the analysis of all data was performed blindly by an investigator (U.S.).

In sum, three series of experiments were performed with two or three groups of six animals each. Table I summarizes the different treatment groups.

In a first set of experiments, two different SMF exposure protocols were evaluated. Therefore, the C57B1/6 mice were randomly assigned to three groups $(n=6$ each) 3 days after tumor inoculation on days 3, 6 and 9 after tumor cell implantation, one group of animals was exposed to $587 \mathrm{mT}$ for $120 \mathrm{~min}$ (group A). Another group of animals was exposed to $587 \mathrm{mT}$ for $35 \mathrm{~min}$ daily on days 3 to 11 (group B). As a control group, six mice were shamexposed outside the SMF (control). In all three groups, $0.2 \mathrm{ml}$ of $0.9 \% \mathrm{NaCl}$ was injected intraperitoneally prior to a SMF exposure or sham exposure on days 3,6 and 9. In a second set of experiments, the combination of SMF exposure with cetuximab treatment was evaluated. Therefore, C57/B16 mice were randomly assigned to three additional groups $(n=6$, each). The animals were treated with $1 \mathrm{mg}$ cetuximab $(0.2 \mathrm{ml}$; Merck KGaA; Darmstadt, Germany) injected intraperitoneally prior to exposure to $587 \mathrm{mT}$ for 120 min (group A+Cet). Another six animals received the same cetuximab treatment, but were exposed to $587 \mathrm{mT}$ for $35 \mathrm{~min}$ daily on days 3 to 11 (group B+Cet). Finally, six animals were treated with cetuximab and sham-exposed to SMF (Cet control group). Figure 1 shows the protocol of the two first series of experiments.

A separate series of experiments was performed to detect relevant immunological effects, as cetuximab is a chimeric (human-murine) antibody applied to immunocompetent mice. One group of six nude mice was treated with cetuximab alone as described for the immunocompetent $\mathrm{C} 57 \mathrm{~B} 1 / 6$ mice. As a control group, a second group of six immunodeficient animals was immobilized for $120 \mathrm{~min}$ outside the magnetic field after having received $0.2 \mathrm{ml}$ of $0.9 \%$ $\mathrm{NaCl}$ intraperitoneally.

In vivo fluorescence microscopy. For intravital microscopy, the awake animals were immobilized in a Perspex tube on a customdesigned stage (Effenberger, Munich, Germany) under a modified Zeiss microscope (Axiotech vario; Zeiss, Oberkochen, Germany). To visualize tumor microcirculation, fluorescein isothiocyanatelabeled dextran (MW 500,000; $0.05-0.1 \mathrm{ml}$ of a $5 \%$ solution in $0.9 \%$ 
SMF exposure:

$120 \mathrm{~min} 587 \mathrm{mT}$

(A, $A+C e t)$

$35 \mathrm{~min} 587 \mathrm{mT}$

(B, B+Cet)

Intraperitoneal injections:

个 1 mg Cetuximab in $2 \mathrm{ml}$ (Cet control, $\mathrm{A}+\mathrm{Cet}, \mathrm{B}+\mathrm{Cet}$, Immunodef. Cet)
or $\mathbf{0 . 9 \%} \mathrm{NaCl}$ in $2 \mathrm{ml}(\mathrm{A}, \mathrm{B}$, Control, Immunodef. control)

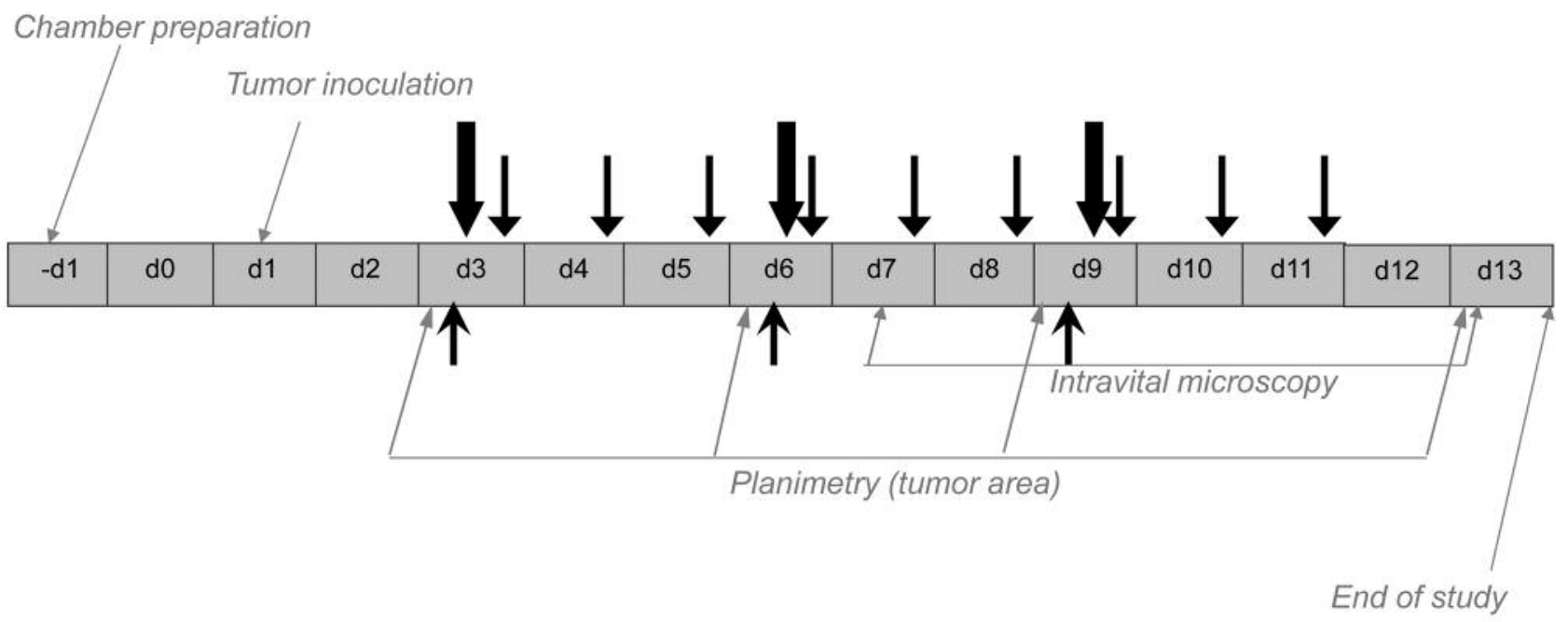

Figure 1. Experimental protocol for C57BL/6 mice: On day 3 after tumor inoculation (d3), animals were randomly assigned to six different treatment groups differing in static magnetic field $(S M F)$ exposure and injected medication. The treatment options are symbolized by black arrows, whereas grey arrows indicate measured parameters. Cet: Cetuximab.

$\mathrm{NaCl}$; Sigma, Deisenhofen, Germany) was injected intravenously into the lateral tail vein as a plasma marker. Rhodamine 6G (Sigma; $0.04 \mathrm{ml}$ of a $0.05 \%$ solution in $0.9 \% \mathrm{NaCl}$ ) was injected intravenously for visualization of leukocyte-endothelial cell interactions. Selective observation of both fluorescent markers was achieved by means of epi-illumination with a $100 \mathrm{~W}$ mercury vapor lamp (FluoArc; Zeiss) and the use of different specific fluorescence filter sets (Set 10 and 14, Zeiss).

For each implanted tumor, six regions of interest (ROI) with a standardized size of $0.458 \mathrm{~mm}^{2}$ were randomly selected. The images were acquired by a CCD-camera (Sony XC-77CE; Sony; Cologne, Germany) and recorded on digital video tape (Sony DVCAM DSV 45P; Sony) for subsequent offline analysis (Cap Image; Zeintl, Heidelberg, Germany). The offline image analysis was described in detail by Zeintl et al. (24) and Klyscz et al. (25). The following parameters were determined in each of the six ROIs investigated per animal: Capillary red blood cell velocity $\left(\mathrm{v}_{\mathrm{RBC}}\right.$ given in $\left.\mathrm{mm} / \mathrm{s}\right)$, capillary diameter (D given in $\mu \mathrm{m}$ ) and functional vessel density (FVD given in $\mathrm{mm} / \mathrm{mm}^{2}$ ). To improve the reliability, vessel diameters and red blood cell velocity were measured in three vessels per ROI.

Leukocyte-endothelial cell interactions were characterized as numbers of flowing leukocytes and rolling cells (at $<50 \%$ of $\mathrm{v}_{\mathrm{RBC}}$ ) crossing a given line in $30 \mathrm{~s}$ and firmly adherent cells (for $>30 \mathrm{~s}$ ) at the vessel wall.
Statistical analysis. All results are presented as the mean \pm standard deviation. Statistical evaluation was performed using SigmaStat software (SigmaStat for Windows, Jandel Scientific, Erkrath, Germany). ANOVA on ranks test followed by the Dunnett test was used for the estimation of stochastic probability in intergroup comparisons. For intragroup comparisons, the Wilcoxon test was used. A $p$-value of less than 0.05 was considered significant.

\section{Results}

SMF exposure modulation. It was the aim of the first subset of experiments to clarify whether fractionation of SMF exposure affects antitumoral efficacy. Representative images of the growing tumors are presented in Figure 2. Figure 3 demonstrates that the tumor sizes of all groups were comparable in the beginning of the study (on average: $3.1 \pm 1.5 \mathrm{~mm}^{2}$ ). However, at the end of the observation period, tumors exposed to SMF for $120 \mathrm{~min}$ on 3 days were significantly smaller $\left(19.2 \pm 4.8 \mathrm{~mm}^{2}\right)$ than controls $\left(35.4 \pm 12.4 \mathrm{~mm}^{2}\right)$, yielding a relative reduction of tumor growth by $46 \%$ compared to control tumors. On the other hand, daily short SMF exposure did not result in significant 


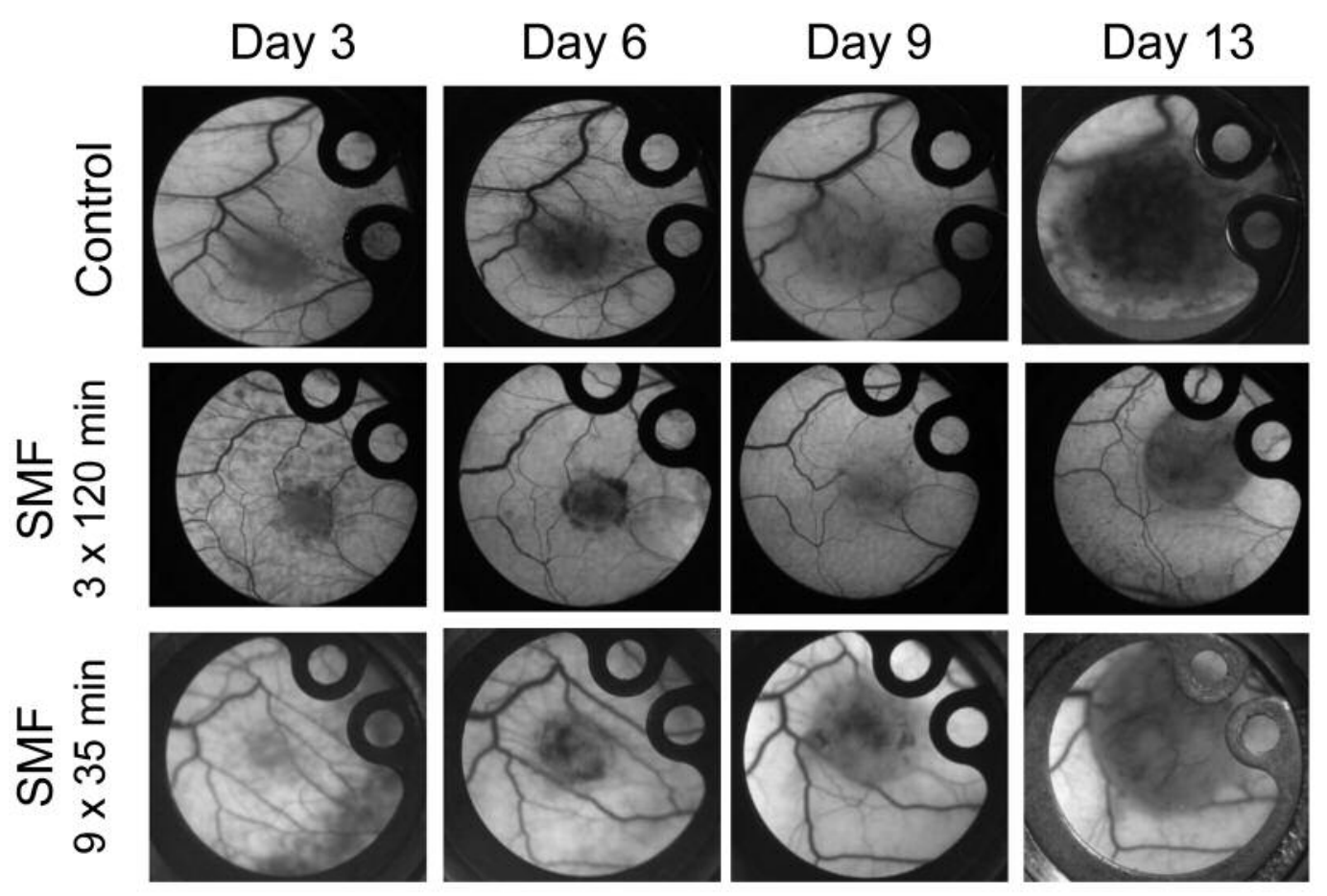

Figure 2. Tumor growth in the dorsal skinfold chamber. Time-lapse sequences clearly show a delay in tumor growth only after three-fold static magnetic field (SMF) exposure for $120 \mathrm{~min}$. Animals exposed daily to SMF for 35 min showed similar tumor growth to that of control animals.

inhibition of tumor growth $\left(31.3 \pm 7.9 \mathrm{~mm}^{2}\right)$, although the total magnetic flux density was almost equal. Therefore, the total exposure time and the total magnetic flux density applied appeared not to be relevant for treatment effects in contrast to exposure duration and frequency.

SMF and targeted therapy. SMF exposure was combined with cetuximab treatment. The combination of SMF and cetuximab did not act in an additive manner. Instead, the extent of tumor growth inhibition by different SMF exposure intervals was unaffected by the additional application of cetuximab (Day 13: A vs. A+Cet: $19.2 \pm 4.8 \mathrm{~mm}^{2}$ vs. $21.3 \pm 5.0 \mathrm{~mm}^{2}$; B vs. B+Cet: $31.3 \pm 7.9 \mathrm{~mm}^{2}$ vs. $32.5 \pm 7.1 \mathrm{~mm}^{2}$ ) (Figure 3). However, cetuximab as monotherapy yielded a strong inhibition of tumor growth $\left(16.7 \pm 4.6 \mathrm{~mm}^{2}\right)$, reflecting a relative reduction of tumor growth by $53 \%$ compared to controls. Hence, SMF appeared to interfere with the effects of cetuximab.

SMF and tumor microcirculation. In order to study the effect of SMF exposure in addition to cetuximab treatment on functional tumor microcirculation, several microcirculatory parameters were measured using in vivo fluorescence microscopy (Table II). On day 7 after tumor cell implantation, all tumors exhibited a chaotic microvascular architecture formed by young microvessels with various diameters and loop formation characteristic of tumor microcirculation.
Except for the animals treated with repeated SMF exposure of $120 \mathrm{~min}$, all groups showed a relative increase in functional vessel density from day 7 to day 13 (A: $-5 \%$, control $+17 \%$, B: $+28 \%$, Cet control: $+5 \%$, A+Cet: $+20 \%$, B+Cet: $+14 \%$ ). Quantitative analysis revealed no significant differences.

Intratumoral leukocyte-endothelial cell interactions. The analysis of leukocyte-endothelial cell interactions revealed no significant differences between the different groups or between different time points for the same group. Even in animals treated with the chimeric antibody cetuximab, there was no increase in leukocyte-endothelial cell interactions.

Immunological effects. To analyze xenogeneic treatment effects of the chimeric antibody cetuximab, experiments in immunodeficient mice were added. In immunodeficient mice, tumor sizes were initially comparable to those in immunocompetent mice. However, tumors grew faster in all immunodeficient mice, independently of the kind of treatment. In immunocompromised mice, the antitumoral activity of cetuximab was less effective, yielding an $18 \%$ reduction of tumor growth compared to $53 \%$ in immunocompetent mice. Again, cetuximab treatment did not provoke relevant changes in leukocyte-endothelial cell interactions in immunodeficient animals compared with immunocompetent animals. 
Table II. Microcirculatory parameters of the different treatment groups: No statistically significant differences were found after intergroup or intragroup testing. Values are given as the mean $\pm S D$. Study groups are fully defined in Table I.

\begin{tabular}{|c|c|c|c|c|c|c|c|}
\hline \multirow[b]{2}{*}{ Parameter } & \multirow[b]{2}{*}{ Day } & \multicolumn{6}{|c|}{ Study group } \\
\hline & & Control $(n=6)$ & $A(n=6)$ & $B(n=6)$ & Cet control $(n=6)$ & $A+C e t(n=6)$ & $B+\operatorname{Cet}(n=6)$ \\
\hline \multirow[t]{2}{*}{$\operatorname{VRBC}(\mathrm{mm} / \mathrm{s})$} & 7 & $0.04 \pm 0.02$ & $0.04 \pm 0.01$ & $0.05 \pm 0.02$ & $0.04 \pm 0.01$ & $0.04 \pm 0.01$ & $0.07 \pm 0.01$ \\
\hline & 13 & $0.05 \pm 0.02$ & $0.05 \pm 0.01$ & $0.04 \pm 0.02$ & $0.05 \pm 0.01$ & $0.05 \pm 0.02$ & $0.05 \pm 0.01$ \\
\hline \multirow[t]{2}{*}{$\mathrm{D}(\mu \mathrm{m})$} & 7 & $9.6 \pm 1.46$ & $10.8 \pm 1.27$ & $11.7 \pm 1.29$ & $9.9 \pm 1.73$ & $10.7 \pm 1.91$ & $11.7 \pm 1.86$ \\
\hline & 13 & $9.6 \pm 2.20$ & $11.3 \pm 1.33$ & $11.6 \pm 3.05$ & $10.5 \pm 2.11$ & $10.9 \pm 1.59$ & $12.4 \pm 2.85$ \\
\hline \multirow[t]{2}{*}{$\mathrm{FVD}\left(\mathrm{mm} / \mathrm{mm}^{2}\right)$} & 7 & $200.4 \pm 20.2$ & $228.9 \pm 38.9$ & $186.6 \pm 36.4$ & $214.0 \pm 39.4$ & $210.4 \pm 42.7$ & $196.2 \pm 26.4$ \\
\hline & 13 & $222.9 \pm 27.6$ & $218.6 \pm 28.9$ & $246.6 \pm 37.5$ & $224.2 \pm 37.8$ & $249.7 \pm 36.3$ & $211.1 \pm 43.5$ \\
\hline \multirow[t]{2}{*}{$\mathrm{Q}\left(\mathrm{mm}^{3} / \mathrm{s}\right)$} & 7 & $1.8 \pm 0.2$ & $2.4 \pm 0.37$ & $3.7 \pm 2.33$ & $2.1 \pm 1.13$ & $2.5 \pm 1.15$ & $4.4 \pm 1.15$ \\
\hline & 13 & $1.9 \pm 0.53$ & $3.4 \pm 1.09$ & $2.6 \pm 1.34$ & $2.3 \pm 1.05$ & $3.1 \pm 2.18$ & $4.0 \pm 1.49$ \\
\hline
\end{tabular}

VRBC: Capillary red blood cell velocity; FVD: functional vessel density; D: capillary diameter; Q: segmental blood flow.

\section{Discussion}

The antitumor, activity of exposure to SMF has already been shown for several cancer entities in vitro (1) as well as in vivo $(3,26)$. However, to our knowledge, there are no data on this subject concerning HNSCC currently treated with targeted therapy (4). The present study demonstrated that SMF exposure reduces tumor growth of squamous cell carcinoma in vivo by up to $46 \%$ compared to sham-exposed tumors. However, this treatment effect was registered after repetitive exposure of $120 \mathrm{~min}$ whereas a shorter more frequent exposure affected tumor growth less. As both fractionation protocols yielded different antitumoral effects despite a comparable net magnetic flux density, the modulation of SMF exposure by frequency and duration appears to be a relevant factor for antitumoral treatment efficacy of SMF.

The underlying mechanism of SMF-induced impairment of tumor cell biology is far from being understood in detail. With regard to the molecular pathways, many potential targets of SMF in tumors have been identified: influence on calcium signaling $(27,28)$, deterioration of antioxidative responses $(29,30)$ and inhibition of angiogenesis $(3,31)$ are well known effects of SMF on tumor biology. In contrast to earlier findings in a different tumor model showing reduced tumor vessel density under SMF exposure, microcirculatory parameters were not significantly affected in our study. At least regarding cell proliferation under SMF exposure, it was recently reported that not only different cell lines, but even different cell densities contribute to the extent of biological effects of SMF (32). Furthermore, tumor angiogenesis is a very complex process and varies not only among different tumor types, but also temporally and spatially within a single tumor (33). In addition, as reported for other anti-vascular therapies, net microvascular density may increase or

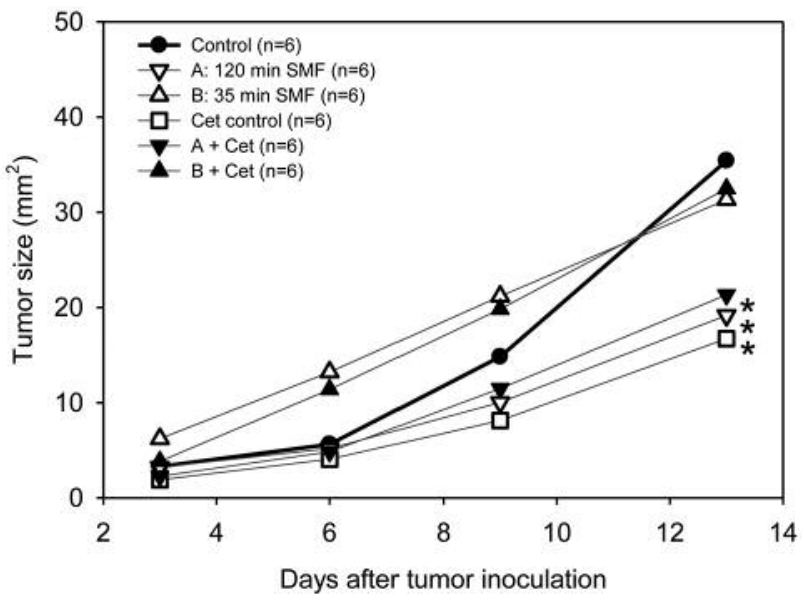

Figure 3. Tumor growth in different treatment groups. At the end of the observation period, the largest tumors were found in control animals, the smallest after cetuximab (Cet) monotherapy. Three-fold static magnetic field (SMF) exposure for $120 \mathrm{~min}$ also led to a significant inhibition of tumor growth, however, the addition of cetuximab conferred no further treatment benefit. *Significantly different at $p<0.05$ vs. control.

decrease - sometimes depending on the tumor model. Whereas the first concept of anti-angiogenic drug therapy aimed to destroy the tumor vasculature, it was recently shown that anti-angiogenic therapy in fact often leads to normalization of tumor vasculature (34). Instead of inducing regression of tumors by starvation, normalization of the tumor vasculature towards a mature phenotype has recently become a major goal of antiangiogenic therapy in order to alleviate tumor hypoxia and slow tumor progression $(33,35)$. This might also explain why FVD was not reduced in tumors treated with cetuximab in our study, although cetuximab is known to have anti-angiogenic activity $(36,37)$. 
Earlier, we clearly demonstrated that changes in microvascular permeability is observed under SMF exposure (19). SMF may be used to open the blood-tumor barrier for concomitant chemotherapy. In the present study, we focused on the effects of a combination of SMF with targeted therapy. Both monotherapies, cetuximab and SMF exposure, resulted in strong tumor growth inhibition. However, the concomitant administration of cetuximab and exposure to SMF revealed interference of both treatment concepts. There is evidence from several in vitro studies that SMF affects the molecular conformation of the EGFR $(6,8)$. Hence, under SMF exposure, cetuximab may be hindered in blocking the receptor effectively. In the same way that this study provides new evidence for interference between SMF exposure and anti-EGFR therapy, one may speculate that the antitumoral effects of SMF exposure as monotherapy might be the result of SMF-mediated functional blockage of EGFR signaling. Zhang et al. indeed reported that a SMF-induced conformation change of the EGFR hindered receptor dimerization, which is critical for ligand-induced activation of the signaling cascade (8). The underlying molecular mechanism may be an SMF-induced conformational and functional deterioration of the target receptor in tumor cell membranes. Whole cell re-orientations were observed under SMF exposure by Higashi et al. (38); spatial and conformational effects on cells and molecules were also reported elsewhere $(39,40)$.

Most studies on cetuximab are carried out on human tumor xenografts in immunodeficient mice. In the present study, we used LLC-1, a murine tumor model, in immunocompetent mice. The fact that cetuximab as single agent displayed significant inhibition of LLC-1-growth might be regarded as the proof of concept that the chimeric antibody also acts on murine tumors. However, further studies are necessary to investigate the exact mechanism of action. In addition, the analysis of leukocyte-endothelial cell interactions provided further evidence that the chimeric antibody does not provoke immunological responses in immunocompetent mice: the leukocyte-endothelial cell interactions in immunocompetent animals treated with cetuximab did not differ remarkably compared to immunocompetent controls. Although there are reports on cetuximab increasing cytokine-driven leukocyte infiltration in vitro $(41,42)$, we were unable to confirm this from our tumor model.

The present study clearly shows how modulation of SMF exposure affects SMF-based carcinoma therapy. Interferences with targeted therapy using cetuximab have to be taken into account in upcoming clinical trials using SMF in EGFRexpressing carcinomas, as for example HNSCCs.

\section{Conflicts of Interest}

The Authors declare no conflict of interest in regard to this study.

\section{Acknowledgements}

This study was supported by an undergraduate funding program (FöFoLe grant 16/2010) of the LMU medical center and by a grant of the foundation 'Tumorforschung Kopf-Hals', Wiesbaden. The sponsor had no influence on study design, on collection, analysis or interpretation of data, on the writing of the manuscript and its publication.

\section{References}

1 Raylman RR, Clavo AC and Wahl RL: Exposure to strong static magnetic field slows the growth of human cancer cells in vitro. Bioelectromagnetics 17: 358-363, 1996.

2 Strieth S, Strelczyk D, Eichhorn ME, Dellian M, Luedemann S, Griebel J, Bellemann M, Berghaus A and Brix G: Static magnetic fields induce blood flow decrease and platelet adherence in tumor microvessels. Cancer Biol Ther 7: 814-819, 2008.

3 Strelczyk D, Eichhorn ME, Luedemann S, Brix G, Dellian M, Berghaus A and Strieth S: Static magnetic fields impair angiogenesis and growth of solid tumors in vivo. Cancer Biol Ther 8: 1756-1762, 2009.

4 Colevas AD: Chemotherapy options for patients with metastatic or recurrent squamous cell carcinoma of the head and neck. J Clin Oncol 24: 2644-2652, 2006.

5 Marrocco BJ, Drost DJ and Prato FS: An optimized head coil design for MR imaging at 0.15 T. Magn Reson Med 5: 143-159, 1987.

6 Jia C, Zhou Z, Liu R, Chen S and Xia R: EGF receptor clustering is induced by a $0.4 \mathrm{MT}$ power frequency magnetic field and blocked by the EGF receptor tyrosine kinase inhibitor PD153035. Bioelectromagnetics 28: 197-207, 2007.

7 Ke XQ, Sun WJ, Lu DQ, Fu YT and Chiang H: 50-Hz magnetic field induces EGF-receptor clustering and activates ras. Int J Rad Biol 84: 413-420, 2008.

8 Zhang L, Wang J, Wang H, Wang W, Li Z, Liu J, Yang X, Ji X, Luo Y, Hu C, Hou Y, He Q, Fang J, Wang J, Liu Q, Li G, Lu Q and Zhang $\mathrm{X}$ : Moderate and strong static magnetic fields directly affect EGFR kinase domain orientation to inhibit cancer cell proliferation. Oncotarget 7: 41527-41539, 2016.

9 Salomon DS, Brandt R, Ciardiello F and Normanno N: Epidermal growth factor-related peptides and their receptors in human malignancies. Crit Rev Oncol Hematol 19: 183-232, 1995.

10 Santini J, Formento JL, Francoual M, Milano G, Schneider M, Dassonville $\mathrm{O}$ and Demard F: Characterization, quantification, and potential clinical value of the epidermal growth factor receptor in head and neck squamous cell carcinomas. Head Neck 13: 132139,1991 .

11 Nicholson RI, Gee JM and Harper ME: EGFR and cancer prognosis. Eur J Cancer 37(Suppl 4): S9-15, 2001.

12 Rubin Grandis J, Melhem MF, Gooding WE, Day R, Holst VA, Wagener MM, Drenning SD and Tweardy DJ: Levels of TGF-alpha and EGFR protein in head and neck squamous cell carcinoma and patient survival. J Natl Cancer Inst 90: 824-832, 1998.

13 Ang KK, Andratschke NH and Milas L: Epidermal growth factor receptor and response of head-and-neck carcinoma to therapy. Int J Radiat Oncol Biol Phys 58: 959-965, 2004.

14 Gupta AK, McKenna WG, Weber CN, Feldman MD, Goldsmith JD, Mick R, Machtay M, Rosenthal DI, Bakanauskas VJ, Cerniglia 
GJ, Bernhard EJ, Weber RS and Muschel RJ: Local recurrence in head and neck cancer: Relationship to radiation resistance and signal transduction. Clin Cancer Res 8: 885-892, 2002.

15 Vermorken JB, Mesia R, Rivera F, Remenar E, Kawecki A, Rottey S, Erfan J, Zabolotnyy D, Kienzer HR, Cupissol D, Peyrade F, Benasso M, Vynnychenko I, De Raucourt D, Bokemeyer C, Schueler A, Amellal N and Hitt R: Platinumbased chemotherapy plus cetuximab in head and neck cancer. $\mathrm{N}$ Engl J Med 359: 1116-1127, 2008.

16 Spivak-Kroizman T, Rotin D, Pinchasi D, Ullrich A, Schlessinger J and Lax I: Heterodimerization of c-ERBB2 with different epidermal growth factor receptor mutants elicits stimulatory or inhibitory responses. J Biol Chem 267: 80568063, 1992.

17 Liu Y, Qi H, Sun RG and Chen WF: An investigation into the combined effect of static magnetic fields and different anticancer drugs on K562 cell membranes. Tumori 97: 386-392, 2011.

18 Gray JR, Frith $\mathrm{CH}$ and Parker JD: In vivo enhancement of chemotherapy with static electric or magnetic fields. Bioelectromagnetics 21: 575-583, 2000.

19 Gellrich D, Becker S and Strieth S: Static magnetic fields increase tumor microvessel leakiness and improve antitumoral efficacy in combination with paclitaxel. Cancer Lett 343: 107-114, 2014.

20 Lehr HA, Leunig M, Menger MD, Nolte D and Messmer K: Dorsal skinfold chamber technique for intravital microscopy in nude mice. Am J Pathol 143: 1055-1062, 1993.

21 Endrich B, Asaishi K, Gotz A and Messmer K: Technical reporta new chamber technique for microvascular studies in unanesthetized hamsters. Res Exp Med 177: 125-134, 1980.

22 Palomo AG, Santana RB, Perez XE, Santana DB, Gabri MR, Monzon KL and Perez AC: Frequent co-expression of EGFR and NEUGCGM3 ganglioside in cancer: Its potential therapeutic implications. Clin Exp Metastasis 33: 717-725, 2016.

23 Brix G, Strieth S, Strelczyk D, Dellian M, Griebel J, Eichhorn ME, Andra W and Bellemann ME: Static magnetic fields affect capillary flow of red blood cells in striated skin muscle. Microcirculation 15: 15-26, 2008.

24 Zeintl H, WR T, Messmer K and Intaglietta M: Static and dynamic microcirculatory video image analysis applied to clinical investigations. Prog Appl Microcirc 11: 1-10, 1986.

25 Klyscz T, Junger M, Jung F and Zeintl H: CAP image-a new kind of computer-assisted video image analysis system for dynamic capillary microscopy. Biomed Tech 42: 168-175, 1997.

26 Tofani S, Cintorino M, Barone D, Berardelli M, De Santi MM, Ferrara A, Orlassino R, Ossola P, Rolfo K, Ronchetto F, Tripodi $\mathrm{SA}$ and Tosi P: Increased mouse survival, tumor growth inhibition and decreased immunoreactive p53 after exposure to magnetic fields. Bioelectromagnetics 23: 230-238, 2002.

27 Fanelli C, Coppola S, Barone R, Colussi C, Gualandi G, Volpe $\mathrm{P}$ and Ghibelli L: Magnetic fields increase cell survival by inhibiting apoptosis via modulation of $\mathrm{Ca}^{2+}$ influx. FASEB $\mathrm{J} 13$ : 95-102, 1999.

28 Teodori L, Gohde W, Valente MG, Tagliaferri F, Coletti D, Perniconi B, Bergamaschi A, Cerella C and Ghibelli L: Static magnetic fields affect calcium fluxes and inhibit stress-induced apoptosis in human glioblastoma cells. Cytometry 49: 143-149, 2002 .
29 Sahebjamei H, Abdolmaleki P and Ghanati F: Effects of magnetic field on the antioxidant enzyme activities of suspension-cultured tobacco cells. Bioelectromagnetics 28: 42-47, 2007.

30 Zhang QM, Tokiwa M, Doi T, Nakahara T, Chang PW, Nakamura N, Hori M, Miyakoshi J and Yonei S: Strong static magnetic field and the induction of mutations through elevated production of reactive oxygen species in Escherichia coli SOXR. Int J Radiat Biol 79: 281-286, 2003.

31 Ruggiero M, Bottaro DP, Liguri G, Gulisano M, Peruzzi B and Pacini S: $0.2 \mathrm{~T}$ magnetic field inhibits angiogenesis in chick embryo chorioallantoic membrane. Bioelectromagnetics 25: 390396, 2004.

32 Zhang L, Ji X, Yang X and Zhang X: Cell type-and densitydependent effect of $1 \mathrm{~T}$ static magnetic field on cell proliferation. Oncotarget 8:13126-13141, 2017.

33 Jain RK: Antiangiogenesis strategies revisited: From starving tumors to alleviating hypoxia. Cancer Cell 26: 605-622, 2014.

34 Maj E, Papiernik D and Wietrzyk J: Antiangiogenic cancer treatment: The great discovery and greater complexity (review). Int J Oncol 49: 1773-1784, 2016.

35 Goel S, Duda DG, Xu L, Munn LL, Boucher Y, Fukumura D and Jain RK: Normalization of the vasculature for treatment of cancer and other diseases. Physiol Rev 91: 1071-1121, 2011.

36 Perrotte P, Matsumoto T, Inoue K, Kuniyasu H, Eve BY, Hicklin DJ, Radinsky R, and Dinney CP: Anti-epidermal growth factor receptor antibody $\mathrm{C} 225$ inhibits angiogenesis in human transitional cell carcinoma growing orthotopically in nude mice. Clin Cancer Res 5: 257-265, 1999.

37 Karashima T, Sweeney P, Slaton JW, Kim SJ, Kedar D, Izawa JI, Fan Z, Pettaway C, Hicklin DJ, Shuin T and Dinney CP: Inhibition of angiogenesis by the antiepidermal growth factor receptor antibody imclone $\mathrm{C} 225$ in androgen-independent prostate cancer growing orthotopically in nude mice. Clin Cancer Res 8: 1253-1264, 2002.

38 Higashi T, Yamagishi A, Takeuchi T, Kawaguchi N, Sagawa S, Onishi S and Date M: Orientation of erythrocytes in a strong static magnetic field. Blood 82: 1328-1334, 1993.

39 Chionna A, Dwikat M, Panzarini E, Tenuzzo B, Carla EC, Verri T, Pagliara P, Abbro L and Dini L: Cell shape and plasma membrane alterations after static magnetic fields exposure. Eur J Histochem 47: 299-308, 2003.

40 Umeno A and Ueno S: Quantitative analysis of adherent cell orientation influenced by strong magnetic fields. IEEE Ttrans Nanobiosci 2: 26-28, 2003.

41 Hoffmann TK, Schirlau K, Sonkoly E, Brandau S, Lang S, Pivarcsi A, Balz V, Muller A, Homey B, Boelke E, Reichert T, Friebe-Hoffmann U, Greve J, Schuler P, Scheckenbach K, Schipper J, Bas M, Whiteside TL and Bier H: A novel mechanism for anti-EGFR antibody action involves chemokinemediated leukocyte infiltration. Int J Cancer 124: 2589-2596, 2009.
Received May 24, 2018

Revised June 8, 2018

Accepted June 11, 2018 